\title{
Utilization of the post - filtration lye from the soda-chlorine-saltpetre method of soda production
}

\author{
Sebastian Drużyński", Mieczysław Trypuć, Urszula Kiełkowska, Krzysztof Mazurek \\ Nicolaus Copernicus University, Faculty of Chemistry, Department of Chemical Technology, Gagarina 7, 87-100 Torun, Poland \\ * Corresponding author: e-mail: sebdru@uni.torun.pl
}

\begin{abstract}
The optimal conditions were determined for the precipitation of ammonium metavanadate from the solutions of ammonium nitrate with the use of sodium metavanadate. The experiments were performed with the molar ratio of salts $\mathrm{NH}_{4} \mathrm{NO}_{3}: \mathrm{NaVO}_{3}$ 1.5:1 at temperatures 293, 303, 313 and $323 \mathrm{~K}$. Based on the obtained results, the optimal time of the process was determined as $5 \mathrm{~h}$ at $293-303 \mathrm{~K}$. Under these conditions, the achieved yield of the precipitation process was $\sim 98.7 \%$, while the contents of the vanadium salts in the post - filtration solution was $\sim 0.02 \%$.
\end{abstract}

Keywords: SCS method, double exchange, ammonium nitrate and ammonium metavanadate.

\section{INTRODUCTION}

Production of sodium carbonate with the Soda-Chlorine-Saltpetre method (SCS) gives valuable by-products - chlorine and solution of ammonium-sodium saltpetre composed of $80 \% \mathrm{NH}_{4} \mathrm{NO}_{3} ; 18 \% \mathrm{NaNO}_{3}$ and $2 \% \mathrm{NaCl}$ as recalculated to solids ${ }^{1}$. That solution is a material for the production of nitrogenous fertilizer. The authors of the SCS method had assumed processing of that liquor by evaporation and crystallization of ammonium-sodium saltpetre. That way is difficult due to a possibility of the uncontrolled decomposition of ammonium nitrate which is catalyzed by the chloride ions remaining in the solution of sodium nitrate after oxidation of sodium chloride with the nitric acid ${ }^{1-3}$.

The aim of the research is to eliminate the danger occurring during the recovery of solid ammonium-sodium nitrate by the evaporation of the post - filtration solution in the process of soda production with the SCS method, as well as to improve the material and economical efficiency of that method. The research on partial utilization of the post - filtration lye from the classic Solvay method, indicates the possibility of the use of sodium metavanadate instead of calcium hydroxide suspension ${ }^{4,5}$. That approach to the utilization of the post - filtration lye from the SCS method is based on a reaction of sodium metavanadate with ammonium nitrate, present in the solution, according to equation (1).

$\mathrm{NH}_{4} \mathrm{NO}_{3}+\mathrm{NaVO}_{3} \leftrightarrow \mathrm{NH}_{4} \mathrm{VO}_{3} \downarrow+\mathrm{NaNO}_{3}$

From the research performed on the mutual solubility of salts for the pairs of exchanging salts $\mathrm{NH}_{4} \mathrm{NO}_{3}+\mathrm{NaVO}_{3}$ $+\mathrm{NaNO}_{3}+\mathrm{NH}_{4} \mathrm{VO}_{3}+\mathrm{H}_{2} \mathrm{O}$ and four ternary subsystems: $\mathrm{NaVO}_{3}+\mathrm{NaNO}_{3}+\mathrm{H}_{2} \mathrm{O}, \mathrm{NH}_{4} \mathrm{VO}_{3}+\mathrm{NH}_{4} \mathrm{NO}_{3}+\mathrm{H}_{2} \mathrm{O}$, $\mathrm{NaNO}_{3}+\mathrm{NH}_{4} \mathrm{NO}_{3}+\mathrm{H}_{2} \mathrm{O}, \mathrm{NH}_{4} \mathrm{VO}_{3}+\mathrm{NaVO}_{3}+\mathrm{H}_{2} \mathrm{O}$ it follows that the highest yield of the conversion reaction is achieved for the composition of the solution corresponding to the ternary invariant point $P_{16,7}$. The solution at this point remains in the equilibrium with three salts in the solid phase: $\mathrm{NaNO}_{3}, \mathrm{NH}_{4} \mathrm{VO}_{3}$ and $\mathrm{NaVO}_{3}$. During the precipitation process, the situation in which the mixture of crystals is obtained instead of the pure product $\left(\mathrm{NH}_{4} \mathrm{VO}_{3}\right)$ should be avoided. Therefore, there is a necessity to determine the physico - chemical parameters such as time, molar ratio of reagents and the initial concentration of the brine of ammonium and sodium nitrates, which cause that the pure product will be obtained with the possibly high yield.

\section{EXPERIMENTAL PART}

\section{Method}

Experiments were conducted at 293, 303, 313 and 323 $\mathrm{K}$ to determine the influence of the addition of sodium nitrate on the reaction yield. The time dependence of the yields $\left(Y_{N H_{+}^{+}}^{(t)}\right)$ of precipitation relative to ammonium ions were calculated according to equation (2) where the excess of the used ammonium nitrate relative to the amount of sodium metavanadate was accounted.

$Y_{N H_{4}^{+}}^{(t)}=\frac{C_{N H_{4}^{+}}^{(0)}-C_{N H_{4}^{+}}^{(t)}}{C_{N H_{4}^{+}}^{(0)}-C_{N H_{4}^{+}}^{\text {excess }}} \cdot 100 \%$

where: $C_{N_{4}^{+}}^{(0)}$ - initial concentration of ammonium ions in the solution,

$C_{N H_{4}^{+}}^{(t)}$ - concentration of ammonium ions after time ( $\mathrm{t}$ ).

$C_{N_{4}^{+}}^{\text {excess }}$ - excess of ammonium ions $(0,830 \mathrm{M})$.

At each temperature, the measurements were performed twice. Ammonium metavanadate was precipitated from the solutions of $2.5 \mathrm{M}$ ammonium nitrate with and without 1.0 $\mathrm{M}$ sodium nitrate. At all temperatures, the molar ratio 1.5:1 of salts $\mathrm{NH}_{4} \mathrm{NO}_{3}: \mathrm{NaVO}_{3}$ was maintained.

Based on the preliminary research on the precipitation of ammonium metavanadate from the ammonium nitrate solutions, the maximum initial concentration of $2.5 \mathrm{M}$ for $\mathrm{NH}_{4} \mathrm{NO}_{3}$ was determined to give the optimal conditions for stirring and the high yield of reaction. For the solutions of higher initial concentration of ammonium nitrate, the reaction mixture was solidified during the dosage of the reagent into the required amount of solid sodium metavanadate, which made the monitoring of the reaction progress impossible.

Ammonium metavanadate was precipitated from the ammonium nitrate solutions in the $200 \mathrm{~cm}^{3}$ Erlenmeyer flask with the grinded neck. The required amount of sodium metavanadate was weighted and then $100 \mathrm{~cm}^{3}$ of the appropriate ammonium nitrate solution was dosed with the one - mark pipette. The flask was corked and thermostated in the water bath with the constant stirring. During that process, the samples of the clear solutions were collected for determination of changes in the solution density, as well as concentration of ammonium and vanadate ions. Samples were collected in the appropriate time intervals: every 1 hour during first 5 hours, then every 24 hours until reaching the equilibrium. 


\section{ANALYTICAL METHODS}

The concentration of ammonium ions was determined with the Ronchese method. It is based on the reaction of formaldehyde with ammonium ions according to equation (3). In that reaction the nitric acid is formed in an amount equivalent to the amount of ammonium ions 8 . $4 \mathrm{NH}_{4} \mathrm{NO}_{3}+6 \mathrm{HCHO} \rightarrow\left(\mathrm{CH}_{2}\right)_{6} \mathrm{~N}_{4}+4 \mathrm{HNO}_{3}+6 \mathrm{H}_{2} \mathrm{O}$

To determine the concentration of vanadate ions, the spectrophotometric method was used with 4-(2pyridylazo) resorcinol (PAR). Vanadate ions form a red - purple complex ion with PAR. That compound has a maximum absorption at $540 \mathrm{~nm}$, and the molar absorption coefficient is $3,6 \cdot 10^{4} \mathrm{dm}^{3} \cdot \mathrm{mol}^{-1} \cdot \mathrm{cm}^{-1}{ }^{9-11}$. The measurement was performed with the double - beam UV - Vis spectrophotometers Hitachi U-2000 and UVD-3000
LABOMED with the $10 \mathrm{~mm}$ quartz absorption cells.

\section{RESULTS AND DISCUSSION}

Changes in ammonium and vanadate ions concentrations, densities and the dependence of yields of the conversion reaction on time and the conditions of the ammonium metavanadate precipitation are presented in table 1.

After the first hour of the conversion process, the achieved yield is approximately $80 \%$ in both cases with and without sodium nitrate (table 1). The excess of ammonium nitrate relative to sodium metavanadate and the increase of temperature does not significantly affect the time the equilibrium is reached. In both cases, in the presence or absence of sodium nitrate, the equilibrium was reached after ca. $20 \mathrm{~h}$.

Table 1. Effect of time and temperature of precipitation on the field of ammonium metavanadate and composition of the post filtration lye

\begin{tabular}{|c|c|c|c|c|c|c|c|}
\hline Time & $\mathrm{NH}_{4}^{+}$ & $\mathrm{V}(\mathrm{V})$ & $Y_{N H_{4}^{+}}^{(t)}$ & Time & $\mathrm{NH}_{4}^{+}$ & $\mathrm{V}(\mathrm{V})$ & $Y_{N H_{4}^{+}}^{(t)}$ \\
\hline (h) & & $\left.\mathrm{dm}^{-3}\right)$ & $(\%)$ & (h) & & $\mathrm{dm}^{-3}$ ) & $(\%)$ \\
\hline \multicolumn{4}{|c|}{ without $\mathrm{NaNO}_{3}$} & \multicolumn{4}{|c|}{$1 \mathrm{M} \mathrm{NaNO}_{3}$} \\
\hline \multicolumn{8}{|c|}{$293 \mathrm{~K}$} \\
\hline 0 & 2.490 & 0 & 0 & 0 & 2.490 & 0 & 0 \\
\hline 0.5 & 1.003 & $7.38 \cdot 10^{-4}$ & 89.6 & 0.5 & 1.249 & $1.04 \cdot 10^{-3}$ & 74.8 \\
\hline 1.5 & 0.958 & $7.74 \cdot 10^{-4}$ & 92.3 & 1.5 & 0.953 & $1.07 \cdot 10^{-3}$ & 92.6 \\
\hline 2.5 & 0.873 & $8.23 \cdot 10^{-4}$ & 97.4 & 2.5 & 0.877 & $1.06 \cdot 10^{-3}$ & 97.2 \\
\hline 3.5 & 0.866 & $8.30 \cdot 10^{-4}$ & 97.8 & 3.5 & 0.866 & $1.13 \cdot 10^{-3}$ & 97.8 \\
\hline 4.5 & 0.842 & $8.50 \cdot 10^{-4}$ & 99.3 & 4.5 & 0.848 & $1.21 \cdot 10^{-3}$ & 98.9 \\
\hline 5.5 & 0.835 & $8.70 \cdot 10^{-4}$ & 99.7 & 5.5 & 0.836 & $1.29 \cdot 10^{-3}$ & 99.6 \\
\hline 21.0 & 0.834 & $9.10 \cdot 10^{-4}$ & 99.8 & 21 & 0.835 & $1.94 \cdot 10^{-3}$ & 99.7 \\
\hline 52.0 & 0.834 & $9.30 \cdot 10^{-4}$ & 99.8 & 52 & 0.834 & $2.21 \cdot 10^{-3}$ & 99,8 \\
\hline 72.0 & 0.834 & $8.91 \cdot 10^{-4}$ & 99.8 & 72 & 0.834 & $2.24 \cdot 10^{-3}$ & 99,8 \\
\hline 98.0 & 0.833 & $9.53 \cdot 10^{-4}$ & 99.8 & 98 & 0.833 & $2.30 \cdot 10^{-3}$ & 99.8 \\
\hline 164 & 0.833 & $9.40 \cdot 10^{-4}$ & 99.8 & 164 & 0.833 & $2.26 \cdot 10^{-3}$ & 99.8 \\
\hline \multicolumn{8}{|c|}{$303 \mathrm{~K}$} \\
\hline 0 & 2.490 & 0 & 0 & 0 & 2.490 & 0 & 0 \\
\hline 0.5 & 1.000 & $1.00 \cdot 10^{-3}$ & 89.8 & 0.5 & 1.167 & $1.19 \cdot 10^{-3}$ & 79.7 \\
\hline 1.5 & 0.903 & $1.04 \cdot 10^{-3}$ & 95.6 & 1.5 & 1.096 & $1.36 \cdot 10^{-3}$ & 84.0 \\
\hline 2.5 & 0.857 & $1.34 \cdot 10^{-3}$ & 98.4 & 2.5 & 1.057 & $1.97 \cdot 10^{-3}$ & 86.3 \\
\hline 3.5 & 0.845 & $1.38 \cdot 10^{-3}$ & 99.1 & 3.5 & 1.023 & $1.97 \cdot 10^{-3}$ & 88.4 \\
\hline 4.5 & 0.838 & $1.45 \cdot 10^{-3}$ & 99.5 & 4.5 & 0.851 & $2.13 \cdot 10^{-3}$ & 98.7 \\
\hline 5.5 & 0.836 & $1.62 \cdot 10^{-3}$ & 99.6 & 5.5 & 0.837 & $2.35 \cdot 10^{-3}$ & 99.6 \\
\hline 51 & 0.834 & $2.60 \cdot 10^{-3}$ & 99.8 & 51 & 0.836 & $3.59 \cdot 10^{-3}$ & 99.6 \\
\hline 75 & 0.834 & $2.52 \cdot 10^{-3}$ & 99.8 & 75 & 0.834 & $3.75 \cdot 10^{-3}$ & 99.8 \\
\hline 97 & 0.833 & $2.49 \cdot 10^{-3}$ & 99.8 & 97 & 0.833 & $3.74 \cdot 10^{-3}$ & 99.8 \\
\hline 166 & 0.833 & $2.50 \cdot 10^{-3}$ & 99.8 & 166 & 0.833 & $3.75 \cdot 10^{-3}$ & 99.8 \\
\hline \multicolumn{8}{|c|}{$313 \mathrm{~K}$} \\
\hline 0 & 2.490 & 0 & 0 & 0 & 2.490 & 0 & 0 \\
\hline 0.5 & 0.963 & $3.49 \cdot 10^{-3}$ & 92.0 & 0.5 & 1.079 & $3.08 \cdot 10^{-3}$ & 85.0 \\
\hline 1.5 & 0.901 & $3.72 \cdot 10^{-3}$ & 95.7 & 1.5 & 0.941 & $4.58 \cdot 10^{-3}$ & 93.3 \\
\hline 2.5 & 0.873 & $3.93 \cdot 10^{-3}$ & 97.4 & 2.5 & 0.903 & $5.08 \cdot 10^{-3}$ & 95.6 \\
\hline 3.5 & 0.860 & $4.12 \cdot 10^{-3}$ & 98.2 & 3.5 & 0.891 & $5.47 \cdot 10^{-3}$ & 96.3 \\
\hline 4.5 & 0.853 & $4.19 \cdot 10^{-3}$ & 98.6 & 4.5 & 0.861 & $5.88 \cdot 10^{-3}$ & 98.1 \\
\hline 5.5 & 0.840 & $4.30 \cdot 10^{-3}$ & 99.4 & 5.5 & 0.842 & $6.17 \cdot 10^{-3}$ & 99.3 \\
\hline 24 & 0.838 & $5.29 \cdot 10^{-3}$ & 99.5 & 24 & 0.836 & $7.48 \cdot 10^{-3}$ & 99.6 \\
\hline 47 & 0.834 & $5.37 \cdot 10^{-3}$ & 99.8 & 47 & 0.834 & $8.19 \cdot 10^{-3}$ & 99.8 \\
\hline 70 & 0.834 & $5.59 \cdot 10^{-3}$ & 99.8 & 70 & 0.834 & $8.19 \cdot 10^{-3}$ & 99.8 \\
\hline 165 & 0.834 & $5.63 \cdot 10^{-3}$ & 99.8 & 165 & 0.834 & $8.23 \cdot 10^{-3}$ & 99.8 \\
\hline \multicolumn{8}{|c|}{$323 \mathrm{~K}$} \\
\hline 0 & 2.490 & 0 & 0 & 0 & 2.490 & 0 & 0 \\
\hline 0.5 & 0.902 & $9.63 \cdot 10^{-3}$ & 95.7 & 0.5 & 0.966 & 0.0117 & 91.8 \\
\hline 1.5 & 0.870 & $9.92 \cdot 10^{-3}$ & 97.6 & 1.5 & 0.890 & 0.0150 & 96.4 \\
\hline 2.5 & 0.865 & 0.0105 & 97.9 & 2.5 & 0.871 & 0.0172 & 97.5 \\
\hline 3.5 & 0.860 & 0.0108 & 98.2 & 3.5 & 0.870 & 0.0183 & 97.6 \\
\hline 4.5 & 0.853 & 0.0109 & 98.6 & 4.5 & 0.879 & 0.0191 & 97.1 \\
\hline 5.5 & 0.847 & 0.0114 & 99.0 & 5.5 & 0.857 & 0.0197 & 98.4 \\
\hline 24.5 & 0.835 & 0.0120 & 99.7 & 24.5 & 0.835 & 0.0231 & 99.7 \\
\hline 48 & 0.834 & 0.0121 & 99.8 & 48 & 0.834 & 0.0228 & 99.8 \\
\hline 72 & 0.834 & 0.0122 & 99.8 & 72 & 0.834 & 0.0232 & 99.8 \\
\hline 145 & 0.834 & 0.0122 & 99.8 & 145 & 0.834 & 0.0234 & 99.8 \\
\hline
\end{tabular}


In the excess of ammonium nitrate relative to sodium metavanadate, it can be concluded that the negative effect of sodium nitrate on the equilibrium is fully eliminated. In all investigated cases, the complete conversion of sodium metavanadate was achieved. The additional advantage is the significant limitation of concentration of vanadate ions caused by the salting out effect of ammonium nitrate on ammonium metavanadate. This limits the production loses of the vanadium compounds.

Analysis of the experimental data (Table 1) indicates that the state close to the equilibrium is reached already after 5 hours of reaction. Continuation of the process longer than $5 \mathrm{~h}$, and the simultaneous decrease in the concentration of ammonium ion in the solution, does not significantly increase the yield of reaction. It should be emphasized that the extension of the time of conversion results in the continuous increase of the vanadate ion concentration, thus increasing loses of vanadium compounds. Therefore, the optimal time of the process of ammonium metavanadate precipitation should be $4-5 \mathrm{~h}$.

Figures 1 and 2 present the calculated yields of reaction and the contents of the vanadium compounds in

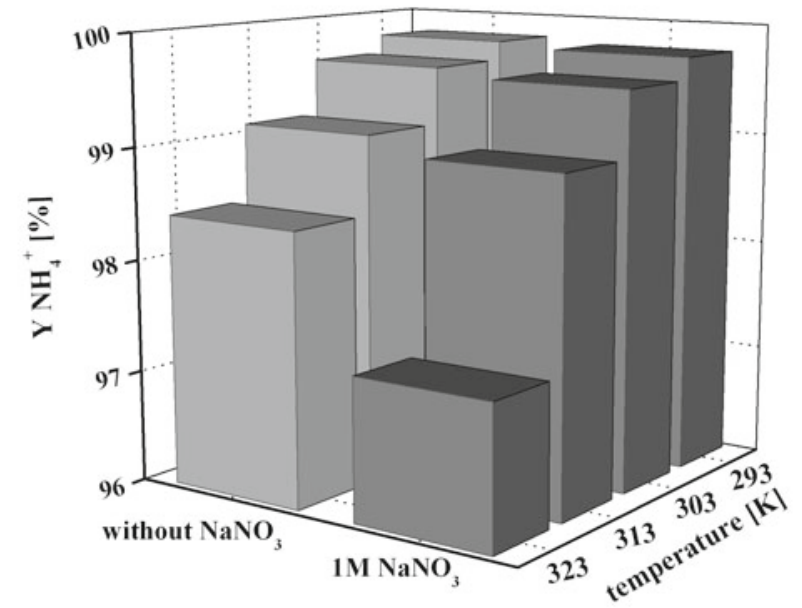

Figure 1. Yield of precipitation of ammonium metavanadate after $5 \mathrm{~h}$ of reaction. Molar ratio $\mathrm{NH}_{4} \mathrm{NO}_{3}: \mathrm{NaVO}_{3}$ $(1.5: 1)$

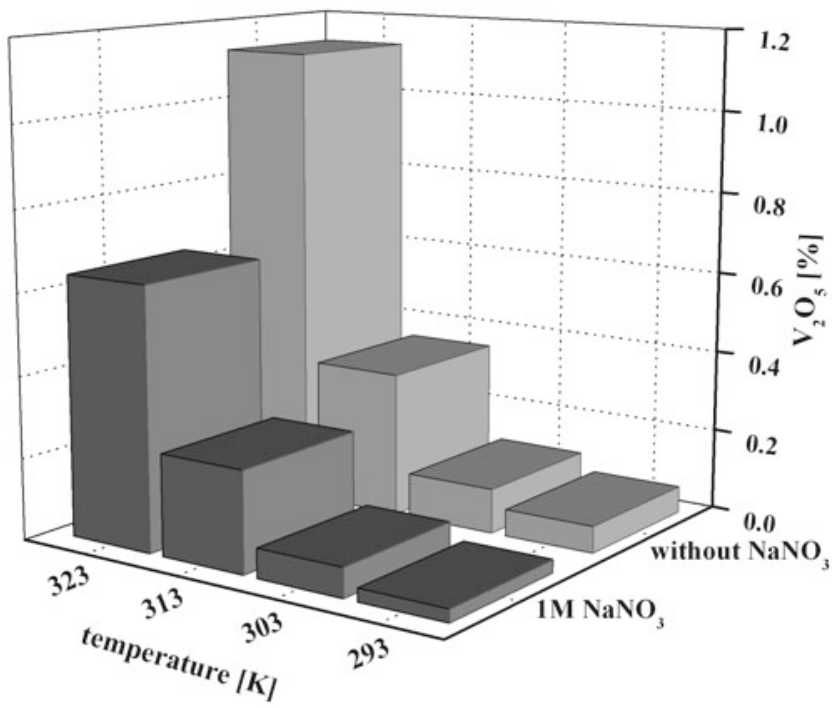

Figure 2. Content of vanadates in sodium nitrate recovered from post - filtration lye after $5 \mathrm{~h}$ of reaction. Molar ratio $\mathrm{NH}_{4} \mathrm{NO}_{3}: \mathrm{NaVO}_{3}(1.5: 1)$. the final product sodium nitrate, for the molar ratio ammonium nitrate to sodium metavanadate of 1.5:1 as found after $5 \mathrm{~h}$ of thermostating.

It has to be stated, that at selected temperatures, the lowering of the reaction yield for the solutions with sodium nitrate is insignificant relative to that for the stoichiometric amounts of reagents. This indicates that the used excess of ammonium nitrate efficiently compensates the negative effect of sodium nitrate on the process yield. Also, Figure 1 reveals that the increase of temperature negatively affects the yield of the conversion reaction, and the effect is more significant for solutions containing sodium nitrate.

The significant aspect of the research is the determination of the conditions at which the obtained product reveals the minimal contamination with the vanadium salts. Contamination of the produced sodium saltpetre with the vanadium compounds determines its usefulness as a fertilizer or is related to the process loses of the vanadium compounds. Figure 2 presents the effect of temperature and the presence of sodium nitrate on the amount of vanadium salts contaminants in sodium nitrate - the solid product after $5 \mathrm{~h}$ of process conducting. The contents of vanadium compounds in the product for the molar ratio of ammonium nitrate to sodium metavanadate $1.5: 1$, as used in the investigations, ranges $0.02-1.20 \%$, as recalculated to $\mathrm{V}_{2} \mathrm{O}_{5}$ (Fig. 2). There is no doubt that the amount of vanadium compounds in the $\mathrm{NaNO}_{3}$ solution increases as temperature increases. The obtained results indicate also that the excess of ammonium nitrate leads to decrease of vanadium salts in the post - reaction solution. Further decrease of the amount of vanadium salts can be achieved by addition of sodium nitrate, which decreases the solubility of ammonium metavanadate. Consequently, in comparison to the solution obtained after the reaction conducted with the use of stoichiometric ratio of reagents, the amount of vanadium salts in the post - reaction solution (1.5:1 molar ratio) is lower by $85-98 \%{ }^{12,13}$.

\section{CONCLUSIONS}

In the post - filtration lye obtained in the SCS method, the presence of sodium nitrate cannot be avoided. That is connected to the yield of carbonization of the ammoniated brines of sodium nitrate, which under optimal conditions is ca. $80 \%{ }^{1}$. Separation of ammonium nitrate from sodium nitrate, by crystallization or other method, prior to the precipitation of ammonium metavanadate is aimless due to the energy requirements of such process. The use of the excess of ammonium nitrate relative to sodium metavanadate allows the compensation of the negative effect of the presence of sodium nitrate on the yield of the precipitation process. However, such a procedure would result in the presence of ammonium nitrate in the final product (up to $25 \%$ as recalculated to the dry mass). Reduction of the amount of ammonium nitrate in the obtained product by $55 \%$ relative to the saltpetre obtained from the SCS method eliminates the risk of explosion during the heat treatment of the solution in a presence of chlorides ${ }^{2,3}$. The negative aspect of such process is, however, the incomplete recovery of ammonia from the post - filtration solution. 
The obtained results indicate that the optimal conditions for precipitation of ammonium metavanadate are as follows:

- initial concentration of ammonium nitrate $2.5 \mathrm{M}$,

- temperature 293-303 K,

- time period 4-5 hours,

- molar ratio of reagents $\mathrm{NH}_{4} \mathrm{NO}_{3}: \mathrm{NaVO}_{3}$ 1.5:1.

The use of the above parameters gives the yield of $\mathrm{NH}_{4} \mathrm{VO}_{3}$ precipitation of $99.6-99.8 \%$, and the contamination of the sodium nitrate solution with vanadium salts at the level of $0.02-0.06 \%$, as recalculated to $\mathrm{V}_{2} \mathrm{O}_{5}$.

\section{LITERATURE CITED}

1. Collaborative paper (1969). Research on the new method of soda production. Nicolaus Copernicus University Publishers, Toruń.

2. Kołaczkowski, A. (1980). Spontaneous decomposition of ammonium nitrate. Scientific Papers, Institute of Inorganic Technology and Mineral Fertilizers, Wrocław Technical University Publishers.

3. Bobrownicki, W., Biskupski, A. \& Kołaczkowski, A. (1977). On the thermal decomposition of ammonium-sodium nitrate. Applied Chemistry, 21, 3-18.

4. Trypuć, M. \& Łyjak, G. (2001). Application of NaVO3 for the utilization of the after-filtration liquor from Solvay's process. Ind. \& Eng. Chem. Res. 40, 2188-2192. DOI: 10.1021/ ie000965r.

5. Trypuć, M. \& Łyjak, G. (2000). Solubility investigations in the $\mathrm{NH}_{4} \mathrm{Cl}+\mathrm{NaVO}_{3}+\mathrm{NH}_{4} \mathrm{VO}_{3}+\mathrm{NaCl}+\mathrm{H}_{2} \mathrm{O}$ system at 303K. J. Chem. Eng. Data, 45, 872-875. DOI: 10.1021/je000091f.

6. Trypuć, M., Drużyński, S. \& Mazurek, K. (2008). Plotting of the solubility isotherm for the $\mathrm{NH}_{4} \mathrm{NO}_{3}+\mathrm{NaVO}_{3}+$ $\mathrm{H}_{2} \mathrm{O}$ system. Pol. J. Chem. Tech., 10(4), 11-14. DOI: 10.2478/ v10026-008-0039-x.

7. Trypuć M. \& Drużyński S. (2009). Phase diagram for the $\mathrm{NH}_{4} \mathrm{NO}_{3}+\mathrm{NaVO}_{3}+\mathrm{NH}_{4} \mathrm{VO}_{3}+\mathrm{NaNO}_{3}+\mathrm{H}_{2} \mathrm{O}$ system at 293 and 303 K. Ind. \& Eng. Chem. Res. 48, 6937-6942. DOI: 10.1021/ie9004139.

8. Struszyński, M. (1957). Analiza ilościowa i techniczna (vol I). Polish Scientific Publishers, Warsaw.

9. Williams, W.J. (1985). Oznaczanie anionów. Polish Scientific Publishers, Warsaw.

10. Sandell, E.B. (1961). Colorimetric determination of traces of metals. Interscience Publishers Inc., New York.

11. Schaeppi, Y. \& Treadwell, W.D. (1948). Über die kolorimetrische Bestimmung der Stöchiometrie einiger Farbkomplexe" Hel. Chim. Acta, 31, 577-588.

12. Trypuć, M. \& Drużyński, S. (2007). Investigation of the solubility in the $\mathrm{NaVO}_{3}-\mathrm{NaNO}_{3}-\mathrm{H}_{2} \mathrm{O}$ system. Ind. \& Eng. Chem. Res. 46, 2688-2692. DOI: 10.1021/ie0614125.

13. Trypuć, M., Drużyński, S., Kiełkowska, U. \& Mazurek, K. (2007). Utilization of the post - filtration lye from the SCS method of soda production" Pol. J. Chem. Tech. 9(4), 59-62. DOI: 10.2478/v10026-007-0091-y. 